\title{
DETERMINATION OF REDUCING COEFFICIENT VALUES OF SEMI-RIGID FRAMES USING ARTIFICIAL NEURAL NETWORK
}

\author{
Soner Şeker, Ali Uğur Öztürk and Celal Kozanoğlu \\ Department of Civil Engineering, Faculty of Engineering \\ Celal Bayar University,45140, \\ Manisa,Turkey \\ sonerseker@bayar.edu.tr
}

\begin{abstract}
Lateral rigidity is a great issue in the view of structural analysis in civil engineering applications such as production of buildings, bridges, dams and roads. Furthermore, the connection properties have a remarkable role on the lateral rigidity and the tendency of structures under service loads. In fact, there aren't any structures with perfectly rigid connections between beams and columns. Therefore, all connections performed by construction process can be defined as semi-rigid as, especially connections in steel structures. The effect of connection type on the lateral rigidity values of structures can be determined by reducing coefficients decreasing lateral rigidity with a certain extent. In the scope of this study, connection flexibility is modeled by linear elastic rotational springs for semi-rigid frames. The reducing coefficients are determined by using a computer program. Results are compared to the values predicted by artificial neural network (ANN) analyses. A strong relationship was established between calculated and predicted values.
\end{abstract}

Key Words- Semi-rigid; Reducing coefficient; Lateral rigidity; Artificial neural network

\section{INTRODUCTION}

In engineering aspects, the knowledge of geometry and mass of a structure and its beam-to-column connection model brings civil and structural engineers to simulate the real behavior under service loads. In conventional design purposes; structures are designed as having rigid connections. Thus the behavior of connections is not rigid.

Structural frames having such flexible connections in which connection flexibility become more important are called semi-rigid frames. Semi-rigid frames are frames for which the beam-to-column joints are neither pinned nor rigid [1]. In reality all frames are semi-rigid, because there is not a frame which has truly pinned and perfectly rigid connections.

In fact, most connections in real steel structures are more or less flexible or semi-rigid. It has been proven so by numerous experimental investigations for frames with semi-rigid connections; that have been carried out in the past [2-4]. 
Structural tendency of frames with semi-rigid connections may be significantly different from rigidly connected frames, particularly those subjected to strong earthquake excitations. Hence the conventional methods of analysis and design of frame structures with ideal connections (fully rigid or pinned) are inadequate, as these often cannot represent real structural behavior. Furthermore, as it is obtained from experimental observations, all beam-column connections were used in current practice possess some stiffness that falls between the two extreme cases of fully rigid and ideally pinned [5]. Thus, the real connections in steel frames should be treated as 'semi-rigid' connections. In the past 20 years, a large number of studies have been conducted on bare steel connections and composite connections [5-11].

By the way, results of theoretical or experimental studies are explained by using some mathematical and numerical methods. Artificial neural network (ANN) analysis is one of these methods. According to the development of computers and software, neural network techniques are considered to use more effectively for simplification of complex problems with large number of computations. ANN analysis is very effective on approximating of structural analysis results in some applications such as optimization. In the scope of this study, the reducing coefficients for lateral rigidity values are predicted by using ANN analysis.

\section{SEMI-RIGID FRAME MODEL AND DETERMINING REDUCING COEFFICIENTS}

The semi-rigid frame model proposed in the present study is one-story frame (Fig. 1.). This model includes a beam with moment of inertia $I_{b}$ and length $L$, and two columns with moment of inertia $I_{c}$, length $h$ and cross-section $A_{c}$. The modulus of elasticity $\mathrm{E}$ is the same in all frame elements.

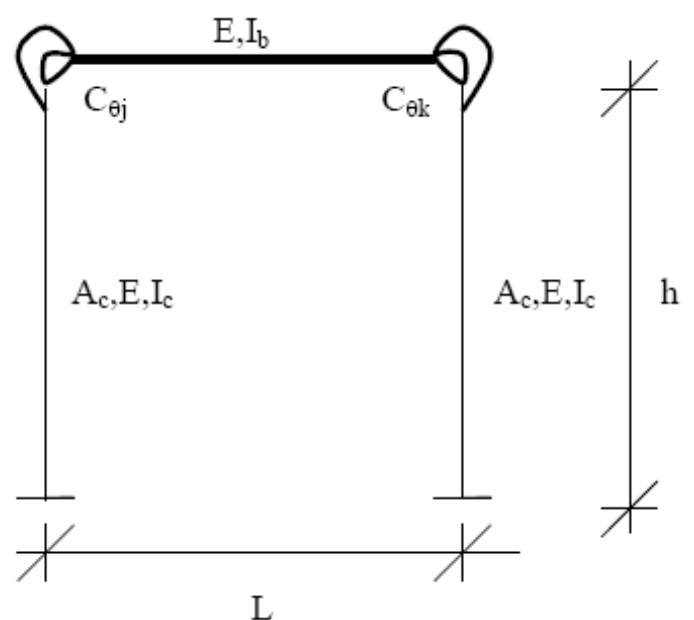

Fig.1. Semi-rigid frame model [12]

The connections are assigned as rotational springs at beam-to-column joints. All deformations are incorporated in this study. Rigidity at the ends of frame element can be defined by the term of rigidity index. For a connection with hinge, rigidity index is zero, and flexural moments do not occur at the ends of a frame 
element. For a rigid connection, this value is infinite, and flexural moments occur at the ends of a frame element [13]. Flexural moments at the two ends for a frame element, with spring coefficients represented by $\mathrm{C}_{\theta \mathrm{j}}$ and $\mathrm{C}_{\theta \mathrm{k}}$.

$$
M_{j f}=C_{\theta k} x \phi \mathrm{j} \quad ; \quad M_{k f}=\mathrm{C}_{\theta k} x \phi \mathrm{k}
$$

where $\mathrm{M}_{\mathrm{jf}}$ and $\mathrm{M}_{\mathrm{kf}}$ are flexural moments, respectively, at $\mathrm{j}$ and $\mathrm{k}$ ends of a frame element, $\phi_{\mathrm{j}}$ and $\phi_{\mathrm{k}}$ are rotations, occurred by rotational springs.

The relationship between spring coefficients and rigidity index can be determined as below, where $R_{j}$ and $R_{k}$ are rigidity index at two ends of a frame element, respectively. Furthermore, Displacements such as rotations at two ends and axial displacement of a semi-rigid frame element are shown in Fig.2. .

$\mathrm{R}_{\mathrm{j}}=\frac{\mathrm{C}_{\theta \mathrm{j}} \mathrm{L}_{\mathrm{i}}}{\mathrm{EI}_{\mathrm{x}}} \quad \mathrm{R}_{\mathrm{k}}=\frac{\mathrm{C}_{\theta \mathrm{k}} \mathrm{L}_{\mathrm{i}}}{\mathrm{EI}_{\mathrm{x}}}$

$\phi_{\mathrm{jyr}}$ and $\phi_{\mathrm{kyr}}$ are total rotations at two ends of a semi-rigid element, $\phi_{\mathrm{jf}}$ ve $\phi_{\mathrm{kf}}$ are rotations occurred without rotational springs at two ends of a semi-rigid element, respectively. $\bar{\phi}_{j}$ and $\bar{\phi}_{k}$ can be written by using equation (1) and equation (2).

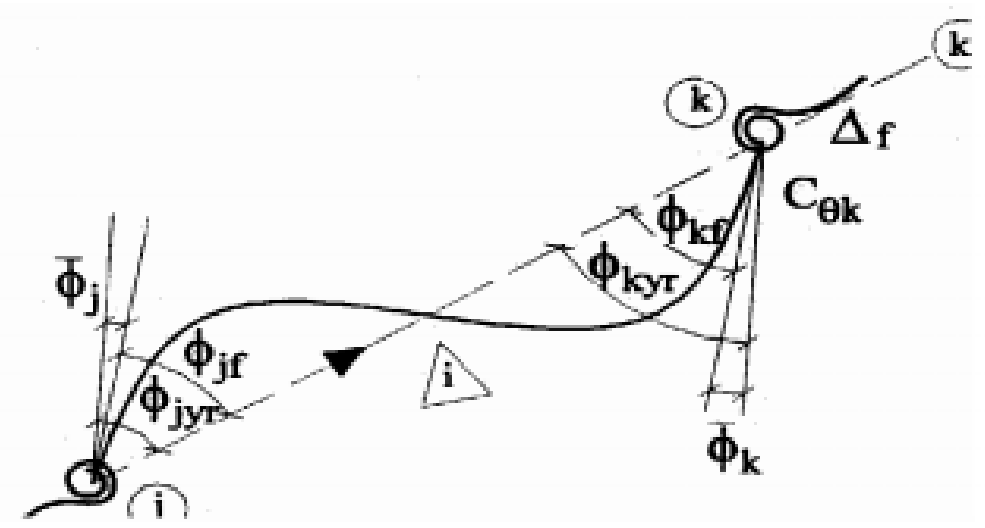

Fig.2. Displacements of a semi-rigid frame element [14]

$\bar{\phi}_{\mathrm{j}}=\frac{\mathrm{M}_{\mathrm{jf}} \mathrm{L}_{\mathrm{i}}}{\mathrm{R}_{\mathrm{j}} \mathrm{EI} \mathrm{x}_{\mathrm{x}}} \quad ; \quad \bar{\phi}_{\mathrm{k}}=\frac{\mathrm{M}_{\mathrm{kf}} \mathrm{L}_{\mathrm{i}}}{\mathrm{R}_{\mathrm{k}} \mathrm{EI} \mathrm{x}_{\mathrm{x}}}$

Using rotational springs, the stiffness matrix relating rigidity index at the ends is given by equation (4) [13]. 
$\left[K_{y r}{ }^{t}\right]=\left[\begin{array}{ccc}\frac{4 E I_{x}}{L_{i}} \beta_{1} & \frac{2 E I_{x}}{L_{i}} \beta_{2} & 0 \\ \frac{2 E I_{x}}{L_{i}} \beta_{2} & \frac{4 E I_{x}}{L_{i}} \beta_{1} & 0 \\ 0 & 0 & \frac{A E}{L_{i}}\end{array}\right]$

where

$$
\begin{array}{lll}
\beta_{1}=\frac{3 \lambda_{1} \lambda_{2}}{\left(4 \lambda_{1}{ }^{2} \lambda_{2}-\lambda_{1}\right)} \quad ; & \beta_{2}=\frac{3}{\left(4 \lambda_{1} \lambda_{2}-1\right)} \quad ; \quad \beta_{3}=\frac{3 \lambda_{1}}{\left(4 \lambda_{1} \lambda_{2}-\lambda_{1}\right)} \\
\lambda_{1}=\left(1+\frac{3}{R_{j}}\right) \quad & \lambda_{2}=\left(1+\frac{3}{R_{k}}\right)
\end{array}
$$

The stiffness matrix of a semi-rigid column element in Fig.1. can be written by

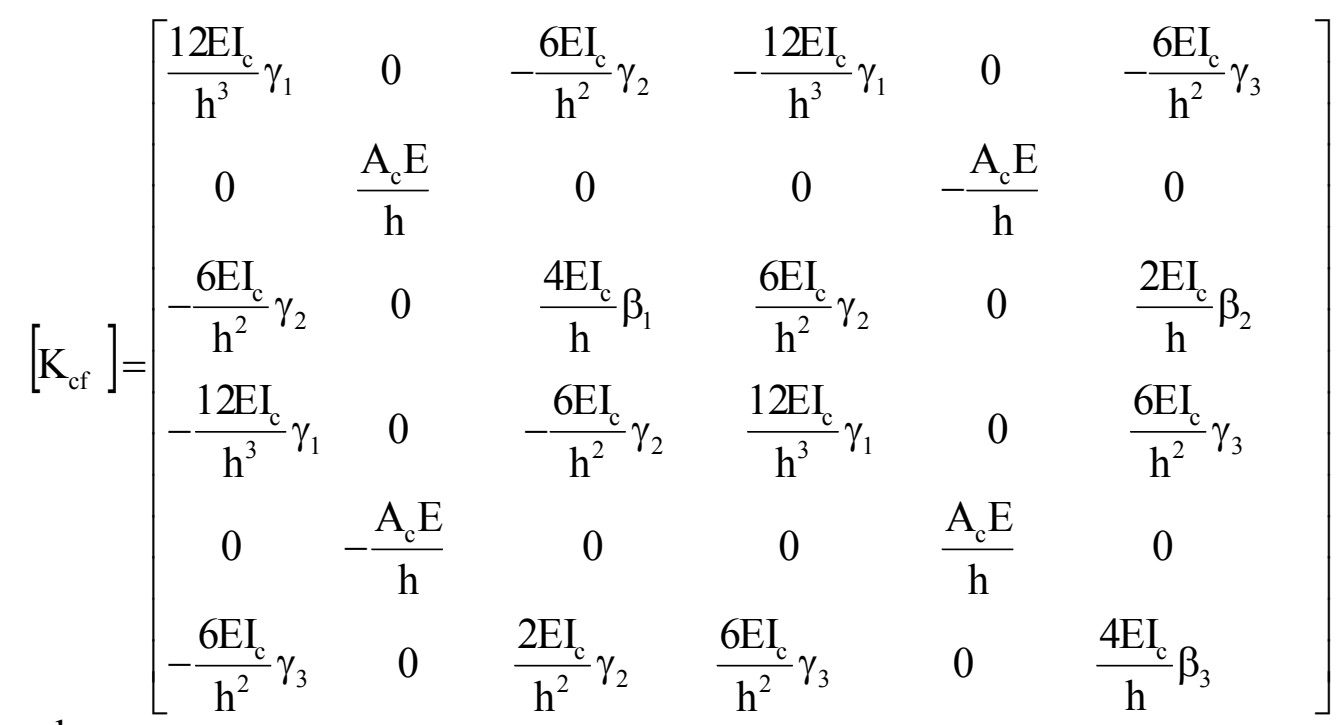

where ;

$\gamma_{1}=\frac{\beta_{1}+\beta_{2}+\beta_{3}}{3} \quad ; \quad \gamma_{2}=\frac{2 \beta_{1}+\beta_{2}}{3} \quad ; \quad \gamma_{3}=\frac{2 \beta_{3}+\beta_{2}}{3}$

The stiffness matrix of a semi-rigid beam element in Fig.1. can be written by 


$$
\left[K_{c f}\right]=\left[\begin{array}{cccccc}
\frac{A_{b} E}{L} & 0 & 0 & -\frac{A_{b} E}{L} & 0 & 0 \\
0 & \frac{12 E I_{b}}{L^{3}} \gamma_{1} & \frac{6 E I_{b}}{L^{2}} \gamma_{3} & 0 & -\frac{12 E I_{b}}{L^{3}} \gamma_{1} & \frac{6 E I_{b}}{L^{2}} \gamma_{3} \\
0 & \frac{6 E I_{b}}{L^{2}} \gamma_{2} & \frac{4 E I_{b}}{L} \beta_{1} & 0 & -\frac{6 E I_{b}}{L^{2}} \gamma_{1} & \frac{2 E I_{b}}{L} \beta_{2} \\
-\frac{A_{b} E}{L} & 0 & 0 & \frac{A_{b} E}{L} & 0 & 0 \\
0 & -\frac{12 E I_{b}}{L^{3}} \gamma_{1} & \frac{6 E I_{b}}{L^{2}} \gamma_{1} & 0 & \frac{12 E I_{b}}{L^{3}} \gamma_{1} & -\frac{6 E I_{b}}{L^{2}} \gamma_{3} \\
0 & \frac{6 E I_{b}}{L^{2}} \gamma_{3} & \frac{2 E I_{b}}{L} \beta_{2} & 0 & -\frac{6 E I_{b}}{L^{2}} \gamma_{3} & \frac{4 E I_{b}}{h} \beta_{3}
\end{array}\right]
$$

The structure stiffness matrix is obtained by assembling the column and beam stiffness matrices described above according to conventional stiffness matrix analysis procedure. One obtains a 6x6 stiffness matrix for the frame of Fig.3.

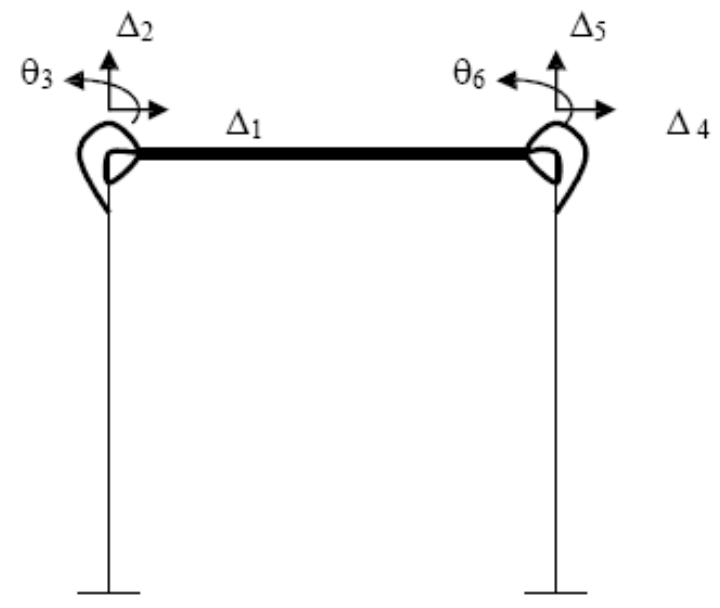

Fig.3. Degres of freedom

By assuming that $\Delta_{1}$ and $\Delta_{4}$ are equal, $\Delta_{4}$ can be eliminated from the frame of Figure 4.The reduced displacements are given by Figure 4. The remaining stiffness matrix is a $5 \times 5$ matrix.

$\{\mathrm{F}\}=[\mathrm{Ksf}] \times\{\delta\}$

The relationship between deformations and forces are given by equation 7 . Solving the above matrix equation for displacements except $\Delta$ and back substituting the result into the first row, the single degree of freedom system stiffness relationship can be written as [15] 


$$
F=\frac{24 E I_{x}}{h^{3}} \alpha_{r} x \Delta
$$

where $\Delta$ is the lateral displacement, and $F$ and $\alpha_{r}$ are the lateral force and reducing coefficient respectively.

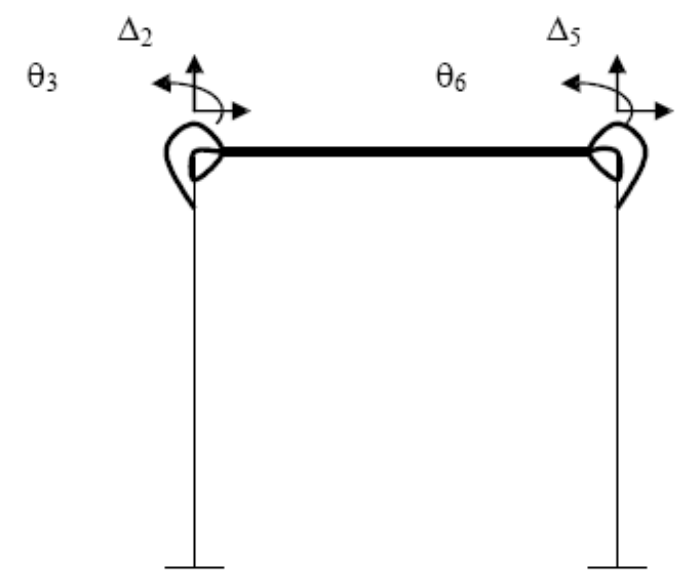

Fig.4. The reduced displacements

\section{ARTIFICIAL NEURAL NETWORK}

Artificial neural networks (ANN) are computing systems that simulate the biological neural systems of the human brain [16]. ANN is known as a complex system of the neurons that are connected each other with different influence level. It is composed of a large number of highly interconnected neurons working in unison to solve specific problems. The approach is based on biological models of the human brain's function, computation is modeled as a large network of interconnected simple processors and ANNs can be trained to recognize input patterns and produce appropriate output responses. The problems that have sufficient training data are suitable for ANN. Prediction of the complex problems and to evaluate new examples fastly are the mainly advantages of ANN.

The prevalent type of artificial neural network consists of three or more layers, including an input layer, an output layer and a number of hidden layers in which neurons are connected to each other with modifiable weighted interconnections.[17] (Fig.5.) The ANN architecture is commonly referred to as a fully interconnected feed forward multilayer perceptron. In addition, there is a bias, which is only connected to neurons in the hidden and output layers with modifiable weighted connections. The number of neurons in each layer may vary depending on the problem.[18]

Neural Networks types are widely used for engineering problems.[19-21] The most widely used neural network learning algorithm is the Back Propagation. This is due to its relatively simplicity, together with its universal approximation capacity. [22] The Back Propagation algorithm defines a systematic way to update the synaptic weights of multi-layer feed forward supervised networks composed of an input layer, that receives the input values, an output layer, which calculates the neural network output, and one or more intermediary layers, so called hidden layers. The back propagation supervised learning process is based on the gradient descent method that 
usually minimizes the sum of squared errors between the target value and the output of the neural network.[23]

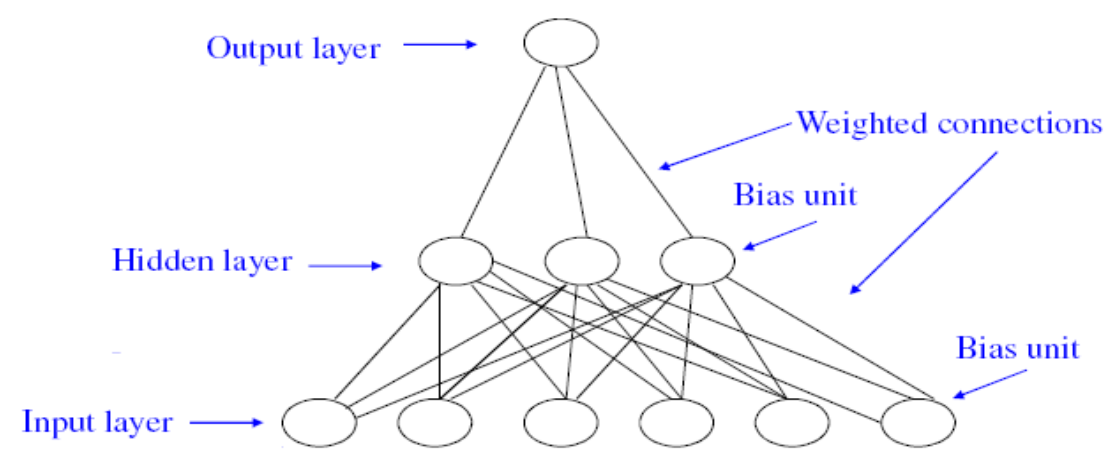

Fig. 5. Structures of a single hidden layer Back Propagation ANN

\section{NUMERICAL ANALYSIS}

In this study, a multilayer feed forward neural network was used. The study is concerned with the prediction of the reducing coefficients of semi-rigid frames using ANN. The database of ANN model was obtained with the formulas that were as mentioned above. The database includes 268 data for training and 67 data for testing the network. Some of the data which used for training and testing set are given in Table (1-3). The most convenient architecture of network was determined as 4-7-1 after trials. The network consists of input layer, single hidden layer and one output layer. Four neurons in input layer, seven neurons in hidden layer and one neuron in output layer take place in architecture of network. Input parameters of the network are; $\mathrm{C}_{\theta j-\mathrm{k}}$ ( spring coefficients), Ib / Ic (ratio of inertia), L ( length of the beams) and $\mathrm{h}$ ( length of the columns). On the other hand output parameter of the network is $\alpha$ (reducing coefficient values). Inputs and outputs are normalized in the (0-1) range by using simple normalization methods. Scaled Conjugate Gradient (SCG) was used as the learning algorithm. In order to find out the optimum result, 1000 iterations were performed.

Table 1. Reducing Coefficients $\left(\mathrm{C}_{\mathrm{q} 1}=\mathrm{C}_{\mathrm{q} 2}=2000 \mathrm{tm} / \mathrm{rd}\right)$

\begin{tabular}{|c|c|c|c|c|c|}
\hline & $\mathbf{0 . 5}$ & $\mathbf{1 . 0}$ & $\mathbf{1 . 5}$ & $\mathbf{2 . 0}$ & $\mathbf{H}$ \\
\hline $\mathbf{0 . 5}$ & 0.0240 & 0.0139 & 0.0100 & 0.0078 & 0.50 \\
\hline $\mathbf{1 . 0}$ & 0.0460 & 0.0273 & 0.0197 & 0.0155 & 1.00 \\
\hline $\mathbf{1 . 5}$ & 0.0662 & 0.0401 & 0.0292 & 0.0231 & 1.50 \\
\hline $\mathbf{2 . 0}$ & 0.0847 & 0.0524 & 0.0384 & 0.0305 & 2.00 \\
\hline $\mathbf{2 . 5}$ & 0.1018 & 0.0643 & 0.0482 & 0.0377 & 2.50 \\
\hline $\mathbf{3 . 0}$ & 0.1177 & 0.0757 & 0.0562 & 0.0449 & 3.00 \\
\hline $\mathbf{3 . 5}$ & 0.1325 & 0.0867 & 0.0648 & 0.0519 & 3.50 \\
\hline
\end{tabular}


Table 2. Reducing Coefficients $\left(\mathrm{C}_{\mathrm{q} 1}=\mathrm{C}_{\mathrm{q} 2}=5000 \mathrm{tm} / \mathrm{rd}\right)$

\begin{tabular}{|c|c|c|c|c|c|}
\hline $\mathbf{I}_{b} / \mathbf{I}_{c}$ & 0.5 & 1.0 & 1.5 & 2.0 & $\mathbf{H}$ \\
\hline 0.5 & 0.0625 & 0.0369 & 0.0264 & 0.0206 & 1.00 \\
\hline 1.0 & 0.1157 & 0.0712 & 0.0516 & 0.0405 & 2.00 \\
\hline 1.5 & 0.1605 & 0.1026 & 0.0754 & 0.0596 & 3.00 \\
\hline 2.0 & 0.1988 & 0.1314 & 0.0978 & 0.0778 & 4.00 \\
\hline 2.5 & 0.2319 & 0.1580 & 0.1189 & 0.0953 & 5.00 \\
\hline 3.0 & 0.2609 & 0.1825 & 0.1390 & 0.1120 & 6.00 \\
\hline 3.5 & 0.2865 & 0.2053 & 0.1579 & 0.1280 & 7.00 \\
\hline
\end{tabular}

Table 3. Reducing Coefficients $\left(\mathrm{C}_{\mathrm{q} 1}=\mathrm{C}_{\mathrm{q} 2}=20000 \mathrm{tm} / \mathrm{rd}\right)$

\begin{tabular}{|c|c|c|c|c|c|}
\hline $\mathbf{2}$ & $\mathbf{0 . 5}$ & $\mathbf{1 . 0}$ & $\mathbf{1 . 5}$ & $\mathbf{2 . 0}$ & $\mathbf{H}$ \\
\hline $\mathbf{0 . 5}$ & 0.1435 & 0.0989 & 0.0763 & 0.0625 & 0.25 \\
\hline $\mathbf{1 . 0}$ & 0.2174 & 0.1689 & 0.1373 & 0.1157 & 0.50 \\
\hline $\mathbf{2 . 0}$ & 0.2625 & 0.2205 & 0.1863 & 0.1605 & 0.75 \\
\hline $\mathbf{2 . 5}$ & 0.2931 & 0.2601 & 0.2265 & 0.1988 & 1.00 \\
\hline $\mathbf{3 . 0}$ & 0.3153 & 0.2917 & 0.2601 & 0.2319 & 1.25 \\
\hline $\mathbf{3 . 5}$ & 0.3321 & 0.3173 & 0.2888 & 0.2609 & 1.50 \\
\hline
\end{tabular}

The performance of training and testing sets of the ANN are given in Fig.6. and Fig.7. As can be seen, the correlation factor for both sets is quite high, which proves the high accuracy of the ANN model with the same trend in the literature [15]

Performance of Training Set

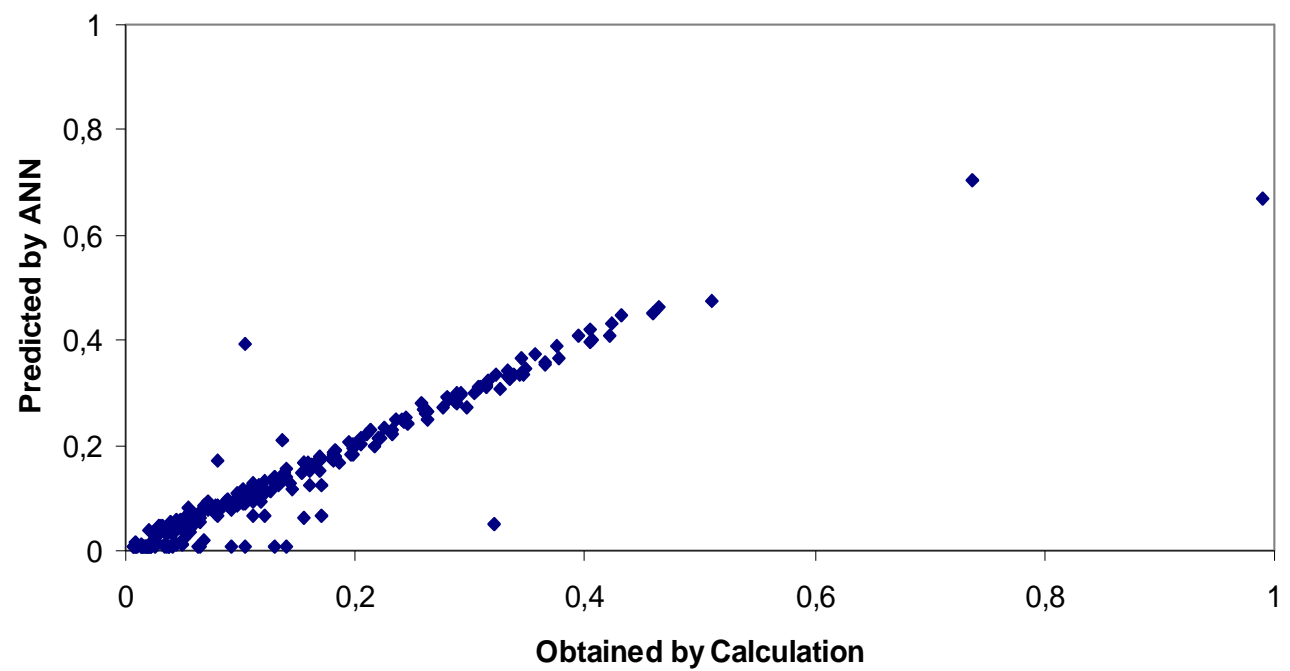

Fig. 6. Performance of Training Set 


\section{Performance of Testing Set}

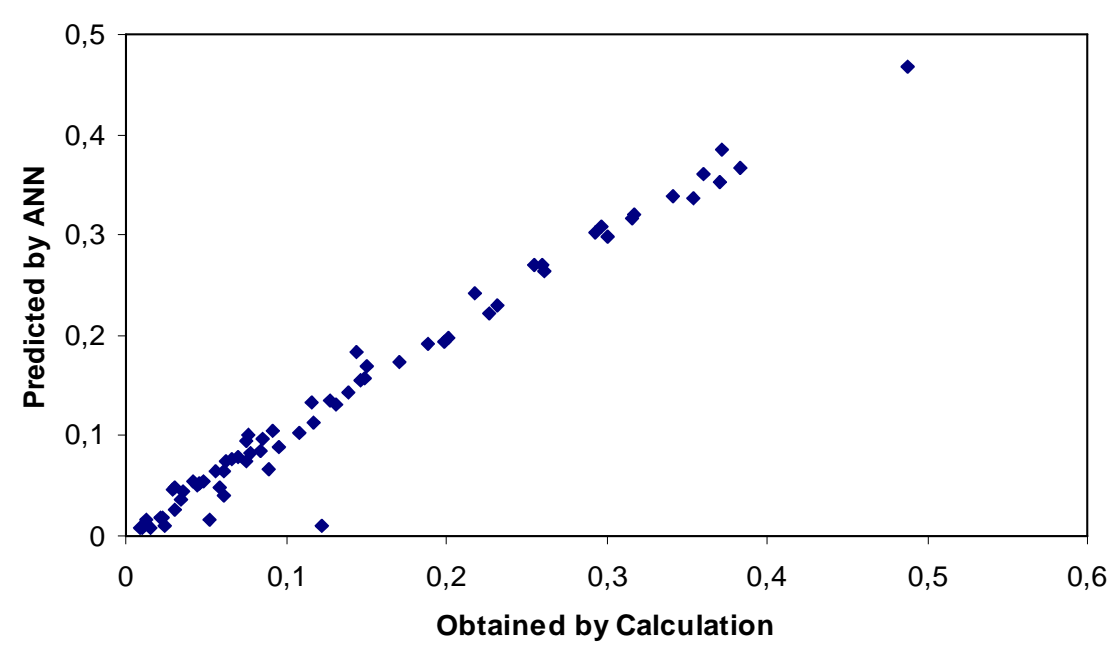

Fig. 7. Performance of Testing Set

\section{CONCLUSION}

In the scope of this study, effects of connection properties of semi-rigid frames on the lateral rigidity values with respect to reducing coefficients are taken into account. The reducing coefficients are determined. Indeed, artificial neural network analysis, being one of the mathematical and numerical methods providing the definition and simulation of the results obtained by both theatrical and experimental studies, is used in order to predict these reducing coefficient values.

The connection flexibility was modeled by linear elastic rotational springs. A computer program by using Matlab was written to obtain the reducing coefficients for the proposed model. Flexible connections were located at the intersection of beam and column. Three different spring coefficients were used in the study. As the linear elastic rotational spring coefficients increase, the lateral rigidity also increases.

The reducing coefficients calculated by the theoretical methods were tried to be predicted by using ANN. The input and output data were normalized between the range of 0 to 1 , in the first step of the ANN analysis. The values predicted by ANN analysis were compared to the values calculated by theoretical method. A strong relationship was established between calculated and predicted values. The correlation coefficient values were determined $\mathrm{R}=0,9564$ and $\mathrm{R}=0,9873$ for training and test process, respectively.

\section{REFERENCES}

1. E.M. Lui and A. Lopes, Dynamic analysis and response of semi rigid frames, Journal of Engineering Structures, 19, 644-654, 1997.

2. Jones SW, Kirby PA, Nethercot DA., The analysis of frames with semirigid connections a state-of-the-art report., Journal of Constructional Steel Research , 3(2), $2-13,1983$

3. Nethercot DA., Steel beam-to-column connections, A review of test data. London: CIRIA, 1985. 
4. Davission JB, Kirby PA, Nethercot DA., Rotational stiffness characteristics of steel beam-to-column connections, Journal of Constructional Steel Research ,8,17-54, 1987

5. Chen WF, Lui EM. , Stability design of steel frames, Boca Raton, Florida: CRC Press, Inc., Corporate Blvd., N. W. , 1991.

6. Bjorhovde R, Colson A, Brozzetti J. , Classification system for beam to column connections , Journal of Structural Engineering ASCE , 116(11) , 3059-76 , 1990

7. Simoes Da Silva L, Simoes R, Cruz JS., Experimental behaviour of end-plate beam to-column composite joints under monotonical loading, Journal of Engineering Structures , 23, 1383-409 , 2001

8. Davison JB, Lam D, Nethercot DA. , Semi-rigid action of composite joints Structural Engineer , 68(24) , 489-99, 1990

9. Xiao Y., Behaviour of composite connections in steel and concrete, Ph.D. thesis. UK: University of Nottingham , 1994.

10. Leon RT. , Semi-rigid composite construction, Journal of Constructional Steel Research , 25 , 99-120, 1990

11. Liew RJY, Teo TH, Shanmugam NE. , Composite joints subject to reversal of loading - Part 1: Experimental study, Journal of Constructional Steel Research , 60(2), 221-46, 2004

12. A.U. Öztürk, Dynamic analysis of semi-rigid frames, Dokuz Eylül University, MSc Thesis , 2003 (in Turkish )

13. W.F. Chen, Y.Goto and R.Liew, Stability design of semi rigid frames, New York, Wiley, 1993.

14. H. H. Çatal, Yapı ve Deprem Mühendisliğinde Matris Yöntemler, Dokuz Eylül Üniversitesi Mühendislik Fak. Yayını No:294 , 4/2002

15. A.U. Öztürk, H. H. Çatal, Dynamic analysis of semi-rigid frames, Mathematical Computational Applications , 10(1) , 1-8, 2005

16. Bishop, C. M., , Neural Networks and Their Applications, Review Scientific Instruments, American Institute of Physics , 65(6) , 1803-1832, 1994

17. Y. Lee, S. H., H. K. Hong, M. W. Kim , Design rules of multi-layer perception, Proc. SPIE, Science of Artificial Neutral Nets in Structural Mechanics. Structural Optimization, 1710, 329-339, 1992.

18. N. Caglar, M. Pala, M. Elmas, D. Mercan Ery1lmaz, A new approach to determine the base shear of steel frame structures, Journal of Constructional Steel Research , 65 , 188-195, 2009

19. W. M. Jenkins, An Introduction to Neural computing for the structural engineer., The Structural Engineer, 75, 38-4,. 1997.

20. K. M. Abdalla and G. E. Stavroulakis, A back propagation neutral network model for semi-rigid steel connections, Microcomputers in Civil Engineering, 10,77-87, 1995.

21. B. Karlık, E. Ozkaya, S. Aydın, S., M. Pakdemirli, Vibration of beam-mass systems using artificial neutral networks, Computers \& Structures, 69, 339-347,1998.

22. Hornik, K., Stinchcombe, M. and White, H., Multilayer feedforward networks are universal approximators, Neural Networks , 2 , 359-366, 1989

23. L. R. O. de Lima , P. C. G. da S. Vellasco ,S. A. L. de Andrade and J. G. S. da Silva, Neural networks assessment of beam-to-column joints, Journal of the Braz. Soc. of Mech. Sci. \& Eng., 27 (3 ), July-September 2005 